\title{
Microalgal pigment ratios in relation to light intensity: implications for chemotaxonomy
}

\author{
C. S. Grant, J. W. Louda* \\ Organic Geochemistry Group, Department of Chemistry and Biochemistry, and The Environmental Sciences Program, \\ Florida Atlantic University, 777 Glades Road, Boca Raton, Florida 33431, USA
}

\begin{abstract}
Pigment-based chemotaxonomy relies upon the assertion that the pigment arrays of mixed microalgal communities (phytoplankton, periphyton, microphytobenthos) can be deconvoluted in ways to provide an estimate of taxon-specific chlorophyll a (chl a) as a proxy for biomass. This relies on having valid chl a:biomarker pigment ratios. However, pigment ratios change for a variety of reasons. We examined the effects of only light intensity (photon flux density, PFD) on the pigment ratios of 10 species in the phyla Cyanobacteria, Chlorophyta, Chromophyta (Bacillariophyceae), Haptophyta, and Pyrrophyta. Chl a:marker pigment versus PFD (30-45 through 1800 umol quanta $\mathrm{m}^{-2} \mathrm{~s}^{-1}$ ) data revealed distinct trends for photosynthetic accessory pigments (PAP) versus photoprotective pigments (PPP). Chl a:PAP class pigments (chl $b$, fucoxanthin, peridinin, echinenone) exhibited relative stability (possibly stoichiometry) with increasing PFD, while chl a:PPP class pigment trends revealed large increases in the relative amounts of the PPP pigments (zeaxanthin, myxoxanthophyll, canthaxanthin, scytonemins). Total chl a cell ${ }^{-1}$ often decreases in concert with increasing PFD and partially or totally explains the decrease in chl a:PPP ratios. We verified that all 'xanthophyll cycle' pigments expressed large and erratic ratios and therefore did not predict chl a levels. We conclude that light (400 to $700 \mathrm{~nm}$ ) measurements taken in the field can offer valuable ancillary data for adjusting pigment-based chemotaxonomic formulae for the study of microalgal communities.
\end{abstract}

KEY WORDS: Chemotaxonomy $\cdot$ Light $\cdot$ Pigments $\cdot$ Biomarker ratios $\cdot$ Chlorophylls $\cdot$ Carotenoids Photoprotection

\section{INTRODUCTION}

The main principle of pigment-based chemotaxonomy rests with the ability to dissect the pigment assemblages of natural microalgal communities, relating taxon-specific biomarker pigments to the amount of chlorophyll a (chl a), as a proxy for biomass, contributed by each group to the total community chl a (Millie et al. 1993, Mackey et al. 1996, Louda 2008). Advances in high performance liquid chromatography (HPLC) have greatly facilitated the separation, identification, and quantitation of chlorophylls and carotenoids (Mantoura \& Llewellyn 1983, Wright \& Jeffrey 1997) and have fostered this methodology.

Taxon-specific pigments, or biomarkers, must be present in discernable ratios to biomass or a proxy for bio- mass, here chl $a$, for the method to yield ecologically useful results (cf. Descy \& Metens 1996). The field of pigment-based chemotaxonomy uses multiple linear regression (MLR) formulae (Gieskes \& Kraay 1983, Wilhelm et al. 1991, Barlow et al. 1993), inverse simultaneous equations (Vidussi et al. 2000, Louda 2008) and advanced algorithms, such as the matrix factorization program CHEMTAX (Mackey et al. 1996) or the recent Bayesian Compositional Estimator (BCE) method of biomarker-based taxonomy (Van den Meersche et al. 2008), for calculating taxon-specific chl a.

The easiest assumption is that chl a:marker pigment ratios do not change throughout a data set or from site to site, with depth and/or day to day. However, as seen from the literature (Gieskes \& Kraay 1983, Wilhelm et al. 1991, Barlow et al. 1993, Mackey et al. 1996, refer- 
ences in Jeffrey et al. 1997, Wright \& Jeffrey 2005) and the data herein, pigment ratios do change in response to various environmental factors. Data from field samples are entered into a multiple regression / multiple simultaneous equation formula or matrix wherein taxon-specific chl $a$ values are the dependent variables and the concentrations of specific marker pigments are the independent measured variables. Chl a:marker pigment molar ratios (Louda 2008) or marker pigment: chl $a$ weight ratios (i.e. CHEMTAX; Mackey et al. 1996, Eker-Develi et al. 2008) are then used as multipliers for calculating the contribution of each major algal group to total phytoplankton biomass, expressed as a function of chl a. Errors stem from the fact that pigment ratios change for a number of reasons, such as growth rate (Goericke \& Montoya 1998, Pinckney et al. 2001), variant species composition (Schlüter et al. 2000, Wright \& Jeffrey 2005), light availability (Wright \& Jeffrey 2005, Leonardos \& Harris 2006), temperature (Greisberger \& Teubner 2007) and the nutritional state of phytoplankton (Mackey et al. 1996, Goericke \& Montoya 1998), amongst others (cf. Eker-Develi et al. 2008 and references therein). The sunscreen pigment scytonemin is also reported to be affected not only by light but by the state of desiccation in certain cyanobacteria (Fleming \& Castenholz 2007). Given the above, the use of pigment ratios needs to be standardized for each system (Lewitus et al. 2005) to provide homogeneous datasets (Mackey et al. 1998). Relative to light, this also can include splitting samples into low versus high light samples (Descy et al. 2000, Rodriguez et al. 2006) or similar depth strata in the sampled area (Mackey et al. 1998).

Pigments that have a light-harvesting function (photosynthetic accessory pigments; PAP) in photosynthesis tend to covary with chl a (Green \& Durnford 1996), while those that appear to have a photoprotective function (photoprotective pigments; PPP) can be expected to increase in high light intensities (Goericke \& Montoya 1998).

Xanthophyll cycle pigments change rapidly in concert with photic flux and light:dark cycles. These include carotenoid $\leftrightarrow$ carotenoid epoxide conversions in chlorophytes (zeaxanthin, ZEA $\leftrightarrow$ antheraxanthin, ANTH $\leftrightarrow$ violaxanthin, VIOLA $;$ Demmig-Adams 1990) and chromophytes (diatoxanthin, DX $\leftrightarrow$ diadinoxanthin, DD; Hager 1980). Given the rapid changes in these series, it can then be argued that none of these pigments can exist in reliable or useable quantitative relationships with chl a. However, the sum of xanthophyll cycle pigments (ZEA+ANTH+VIOLA or DD + DX) may yield meaningful information as to the chemotaxonomic and/or light history of microalgal communities and indicate specific biomarker ratio values to be used when a certain photic history is inferred. The 'epoxidation state' (EPS) of the xanthophylls cycle (EPS = $[\text { VIOLA + } 0.5 \text { ANTH] / [VIOLA + ANTH + ZEA] }]_{\text {Thayer }}$ \& Bjorkman 1992) may also provide insight as to light history over the short ( hours to days) term.

Additional complications in pigment interpretations arise if senescent, dead, or grazed materials are present in the natural seston, periphyton, or microphytobenthos being analyzed. In these cases, the presence of pheopigments may confound analysis of the data (Louda 2008) as pigments such as peridinin (PERI; dinoflagellates) and fucoxanthin (FUCO; chrysophytes, diatoms) degrade faster than xanthophylls, such as ZEA and lutein (LUT; Leavitt \& Carpenter 1990, Louda et al. 1998, 2002, Patoine \& Leavitt 2006).

Variations of pigment content within various taxa, even at the species level, are often ignored in biomass estimations. Thus, a need exists to define ratios and especially their variability in ways that will allow reliable/verifiable estimates of chl a contributions for each taxon (Peeken 1997, Jeffrey et al. 1999) or 'plankton functional group' (PFG; Paerl et al. 2003), as summarized in this quote: 'The biggest problem remaining for all such techniques is the paucity of data available for pigment ratios of major species over a wide range of light and nutrient regimes' (Jeffrey et al. 1999, p. 890). This is especially critical since past studies (Carreto et al. 2008) have shown a logarithmic decrease in pigments (e.g. chl a per cell) and decreasing chl a:marker pigment ratios with increasing irradiance.

In the present study, we evaluated irradiance, an easily measured laboratory and field parameter, as a driver for changes in chl a:biomarker pigment ratios. Data were collected on pigment ratios and, where possible, pigment contents cell ${ }^{-1}$. Ten algal species (3 cyanobacteria, 2 chlorophytes, 2 diatoms, 2 dinoflagellates, and 1 haptophyte) were investigated under photosynthetically active radiation (PAR) irradiances of 30-45, 108-120, 300, and 1600-1800 $\mu \mathrm{mol}$ quanta $\mathrm{m}^{-2} \mathrm{~s}^{-1}$. These we classify as low, moderate, high, and intense light conditions, respectively. Other growth parameters were not altered, and harvesting occurred during nutrient replete conditions.

\section{MATERIALS AND METHODS}

Experimental organisms. Freshwater and marine microalgal species were purchased (Carolina Biological Supply Company).

Cyanobacteria: Lyngbya sp. (fresh), Scytonema hoffmanni (fresh), Anacystis nidulans (also known as Synechococcus sp.: marine).

Chlorophyta: Closterium acerosum (fresh), Cosmarium turpinii (fresh).

Chrysophyta, Bacilliariophyceae: Navicula sp. (fresh), Phaeodactylum sp. (marine). 
Chrysophyta, Prymnesiophyceae: Isochrysis galbana (also known as 'T-ISO': marine).

Pyrrophyta, Dinophyceae: Gymnodinium sp. (marine), Amphidinium carteri (marine). Cross contamination of the Gymnodinium sp. with A. carteri (PERI) as supplied precluded any meaningful interpretation of biomarker (fucoxanthin) data for Gymnodinium sp.

Culture conditions. Algae were cultured in $50 \mathrm{ml}$ lots within $125 \mathrm{ml}$ baffled bottom flasks (low light) or tissue culture flasks (moderate to intense). Light levels are given here as low (30-44.5 $\mu \mathrm{mol}$ quanta $\left.\mathrm{m}^{-2} \mathrm{~s}^{-1}\right)$, moderate (108-120 $\mu \mathrm{mol}$ quanta $\mathrm{m}^{-2} \mathrm{~s}^{-1}$, high $(300 \mu \mathrm{mol}$ quanta $\mathrm{m}^{-2} \mathrm{~s}^{-1}$ ), and intense (1600-1800 $\mu$ mol quanta $\mathrm{m}^{-2} \mathrm{~s}^{-1}$ ). Light sources included sunlight quality (Verilux Instant Sun ${ }^{\mathrm{TM}}$ ), Full Spectrum ${ }^{\mathrm{TM}}$ (ValuTek), 'aquarium' (Phillips), and UVA fluorescent tubes (Sylvania Gro-Lux ${ }^{\mathrm{TM}}$ ). Low light illumination (30 to $44 \mu \mathrm{mol}$ quanta $\mathrm{m}^{-2} \mathrm{~s}^{-1}$ ) of the $125 \mathrm{ml}$ flasks in a rotating ( $\left.60 \mathrm{rpm}\right)$ water bath was from overhead using 1 each sunlight and aquarium tubes set on a 12:12 h light:dark cycle. Low light illumination of the flat (tissue culture) flasks was from above and below using sunlight and aquarium quality $20 \mathrm{~W}$ bulbs, 1 each above and below a flat wire mesh rack. Moderate (110-120 $\mu \mathrm{mol}$ quanta $\mathrm{m}^{-2} \mathrm{~s}^{-1}$ ) and high (300 $\mu \mathrm{mol}$ quanta $\mathrm{m}^{-2} \mathrm{~s}^{-1}$ ) light conditions were achieved within a temperature controlled $\left(25^{\circ} \mathrm{C}\right)$ Revco-Harris growth chamber in which 6 sunlight quality fluorescent plus 6 Full Spectrum ${ }^{\mathrm{TM}}$ fluorescent bulbs were placed around the shelf holding the flasks (maximum of 3 bulbs each, top, bottom, and both sides). Intense illumination (1600-1800 $\mu$ mol quanta $\mathrm{m}^{-2} \mathrm{~s}^{-1}$ ) was achieved within a Percival Model E36HID growth chamber equipped with full spectrum halogen lights to which 4 UVA fluorescent tubes were added. We could not directly measure the UVA irradiance within the flat NUNCLON $\Delta$ polystyrene culture flasks (\#153732). However, both the published UV/Vis transmission spectrum of NUNCLON $\Delta$ polystyrene (www.nuncbrand.com) and that which we recorded (200-800 $\mathrm{nm}$ ) revealed 52\% $\mathrm{T}$ (percent transmission) at $315 \mathrm{~nm}, 56 \%$ at $320 \mathrm{~nm}$, and $87 \%$ at $400 \mathrm{~nm}$, covering the range of UVA. Transmission of visible light from 400 to $800 \mathrm{~nm}$ was $90 \% \mathrm{~T}$. All growth was at $25 \pm 1.5^{\circ} \mathrm{C}$. Light (PAR radiation: 400-700 nm) was measured with a $4 \pi$ spherical radiometer and Li-Cor LI-250 light meter.

Algal culturing. Freshwater algae were cultured in media prepared from the Carolina Biological Supply Company materials: $20 \mathrm{ml}$ of Alga-Gro (f/2) concentrate (\#153751) was added to $980 \mathrm{ml}$ of spring (karst) water (Zephyrhills, Nestle) and autoclaved $\left(122^{\circ} \mathrm{C}\right.$, 2 atm, $45 \mathrm{~min}$ ). This was used for the culture of all freshwater species except the following 2 . In the case of the diatom Navicula sp., $20 \mathrm{mg} \mathrm{l}^{-1}$ of sodium silicate were added prior to sterilization. For the culture of the cyanobacterium Scytonema hoffmanii, sterile soil water extract (\# 153785) was added to the pre-sterilized media given above.

Marine species, except as given below, were cultured in Carolina Biological Supply Alga-Gro (f/2) seawater medium (\#153754). The marine cyanobacterium Anacystis nidulans ( Synechococcus sp.) was cultured in Allen's medium (\#153745). Alga-Gro medium is Guillard's (1975) f/2 medium (Basch 1996).

Growth monitoring. Cell densities were monitored every 2 to $4 \mathrm{~d}$ by aseptically removing a small aliquot ( $\sim 0.5$ to $1.0 \mathrm{ml}$ ) of the culture, following a thorough but gentle mixing of the culture, and then measuring absorbency (AU, optical density, OD) at $430 \mathrm{~nm}$ versus time (days of growth); this allowed sampling during early to mid logarithmic growth. Cross checks of the OD method of growth monitoring were performed using either electronic cell counting with a Coulter Model ZM cell counter or microscopically with a hemocytometer for single-celled or filamentous forms, respectively. Growth periods ranged between 5 and $26 \mathrm{~d}$, depending upon species, and varied inversely with light intensities. As cultures were never taken to the retardation or stationary phases, we consider sampling to have occurred during nutrient replete conditions.

Replicate analyses ( $\mathrm{N}=5$ to 13 ) of each species/light level represent separate cultures, not samples from the same culture. This was done in order to allow growth and pigment variability to be expressed. Additionally, this allowed cultures to not become overly dense, ensuring both nutrient replete conditions as well as precluding significant self-shading while still providing excellent pigment yields when the entire culture was harvested.

Pigment extraction and analyses. All sample handling and pigment analyses were carried out under dim yellow light conditions to prevent photo-oxidative alteration/isomerization of pigments. Extraction and HPLC conditions followed those previously published (Louda et al. 1998, 2000, 2002, Hagerthey et al. 2006).

HPLC data handling. Pigment identities were determined based on retention time and spectral absorbance from a photodiode array (PDA) detector. The retention times and spectral absorbance of the pigments were compared to those from $>90$ standards (Louda et al. 2002, Louda 2008) for final confirmation. Pigment standards were obtained through partial synthesis or derivatization (Louda 1993), and many were purchased from DHI Water and Environment and SigmaAldrich as single compounds or known qualitative mixtures.

Quantification relied on the Beer-Lambert relation wherein peak areas at an appropriate wavelength $(440 \mathrm{~nm}=$ chlorophylls, carotenoids; $410 \mathrm{~nm}=$ pheo- 
pigments, $394 \mathrm{~nm}=$ internal standard) were divided by an extinction coefficient from the literature (e.g. Britton 1995, Jeffrey 1997 and references in each). Extinction coefficients that were used but did not correspond to the exact maximum for which they were reported were adjusted by the ratio of absorbance at the HPLC monitoring/integrating wavelength to that at the wavelength of the reported coefficient. This quantitation protocol was verified using solutions of authentic known pigments that were prepared using standard spectrophotometric techniques.

Chl a-epi (epimer, chl $a^{\prime}$ ) and ECHIN partially coelute from the $300 \mathrm{~mm} \mathrm{C}-18$ column used here (cf. Louda et al. 1998, $150 \mathrm{~mm}$ column). ECHIN and chl $a^{\prime}$ were 'colorimetrically separated' by manual integration at 460 and $666 \mathrm{~nm}$, respectively, thus eliminating their spectral overlap at $440 \mathrm{~nm}$ and allowing valid individual quantitation using wavelength adjusted extinction coefficients. The extremely small absorbance of chl $a^{\prime}$ at $460 \mathrm{~nm}$ was ignored during the calculation of echinenone. Tests with known mixtures confirmed this approach. LUT and ZEA were baseline separated on our HPLC system (Louda et al. 2002).

The chl a:biomarker pigment ratios of the 10 algal species were calculated from the concentrations of individual chlorophylls and carotenoids in cultures grown at low, moderate, high, and intense irradiance levels. Replicate analyses of each species at the various light intensities were made as follows: low $(\mathrm{N}=7)$, moderate $(\mathrm{N}=11)$, high $(\mathrm{N}=5)$ and intense $(\mathrm{N}=13)$. Data were plotted as mean $\pm \mathrm{SD}$. All trends were initially plotted using linear, log normal, power, and exponential trend lines. In all cases, except chl a:DD (power), log normal trends gave significantly higher $\mathrm{R}^{2}$ values.

Herein we report molar, not weight, ratios for all pigment data presented, as they are biochemically more appropriate than simple weight ratios. For the w/w ratios and their inverses (i.e. CHEMTAX), see Tables S1 \& S2 in the Supplement at www. int-res.com/articles/suppl/b011p127_supp.pdf. Further, when we quote or compare our ratios to literature values, we have converted the reported inverse w/w ratios to our molar chl a:marker pigment format. That is, the goal was to predict taxon-specific chl a contributions.

\section{RESULTS}

\section{Cyanobacteria}

Pigments common to the 3 cyanobacteria studied were chlorophyllide $a$ (chlide $a$ ), ZEA, chl $a$-allomer (chl $a$-allo), chl $a, \operatorname{chl} a^{\prime}$, and $\beta$-carotene (BETA).

\section{Anacystis nidulans (cf. Synechococcus sp.)}

This common unicellular cyanobacterium was previously called A. nidulans R2 and is likely Synechococcus PCC 7942 or S. elongatus (PCC6301) in the Expert Protein Analysis System (ExPASy) proteomics server of the Swiss Institute of Bioinformatics (www.expasy.ch). $S$. elongatus is a bloom-forming organism in Florida Bay and its estuarine margins (Phlips et al. 1999) and exhibits changing chl a:ZEA ratios with light regimes (Louda 2008).

The only pigment available as a biomarker for this species was ZEA. Chl a:ZEA ratios declined from about 3.0:1 in low to about 1.5:1 in moderate to high light, and then dropped slowly to about 1.1:1 at the highest light levels (Fig. 1a). As ZEA was about 1 to 2 orders of magnitude more abundant than BETA, a similar trend was likewise found for chl a:total carotenoids. LazaMartinez et al. (2007) studied Synechococcus sp. grown in $100 \mu \mathrm{mol} \mathrm{m}^{-2} \mathrm{~s}^{-1}$ in a $14 \mathrm{~L}: 10 \mathrm{D}$ regime and reported a weight ratio of ZEA:chl $a$ of 0.836 (thus chl $a$ :ZEA = 1.196), corresponding to a molar ratio of chl a:ZEA of $0.76: 1$.

\section{Lyngbya sp.}

In addition to the pigments found in Anacystis nidulans, Lyngbya sp. also contained myxol (MYXOL), a less polar myxoxanthophyll (MYXO-NP), myxoxanthophyll (MYXO, myxol-2'-glycoside), echinenone (ECHIN), and BETA. MYXO has a sugar moiety (often rhamnose) attached, whereas MYXOL is the non-glycosylated alcohol (Francis et al. 1970, cf. Mohamed et al. 2005).

Chl a:ECHIN ratios (Fig. 1b) decreased from about 22:1 in moderate and high light to around 17:1 in intense light. No low light cultures grew or survived for this species. Chl a: ECHIN of about 22:1 appears to best represent Lyngbya sp. biomass in moderate to high light conditions.

Chl a:ZEA ratios (Fig. 1b) decreased from about 17 to 12 to 5:1 with increasing light intensity. Chl a:MYXO (Fig. 1c) values went from about 11:1 to 8:1 with increasing light, but trends were poorly correlated.

\section{Scytonema hoffmanii}

Pigments in S. hoffmanii were as found for Lyngbya sp. with the addition of certain sunscreen pigments.

As with the other filamentous cyanobacterium Lyngbya sp., the biomarker exhibiting the best stability in its relation to chl a was ECHIN (Fig. 1d). The error bars determined for these data encompass a ratio of about 11:1. 

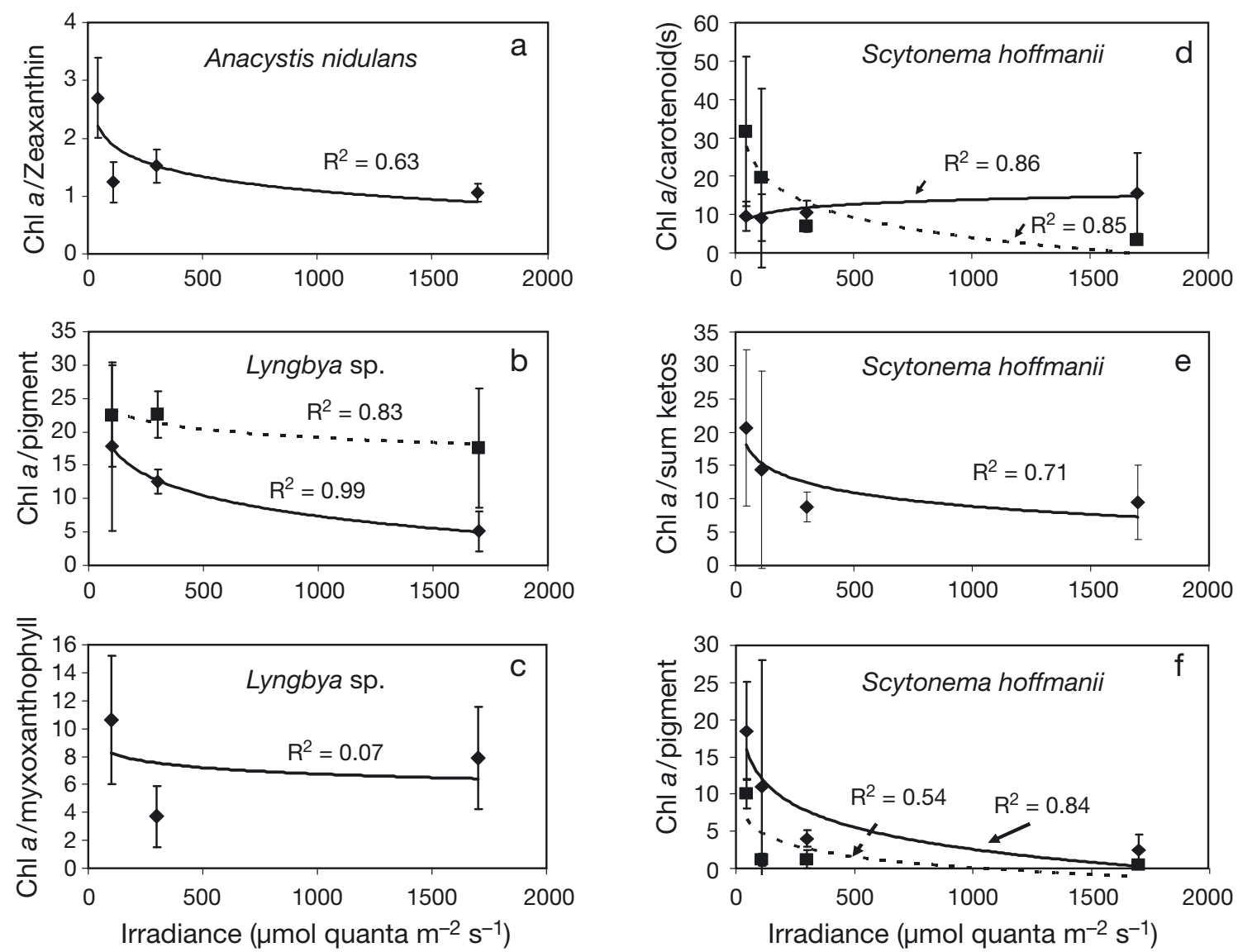

Fig. 1. Pigment ratios versus photic flux density (PFD) for cyanobacteria: (a) Anacystis nidulans; chl a:zeaxanthin (ZEA). (b,c) Lyngbya sp.; (b) chl a:ZEA (diamonds, solid line) and chl a: echinenone (ECHIN; squares, dotted lined), (c) chl a: myxoxanthophyll (MYXO). (d-f) Scytonema hoffmanii; (d) chl a:ECHIN (diamonds, solid line) and chl a:canthaxanthin (CANTH; squares, dashed line), (e) chl a:sum ketocarotenoids (= ECHIN + CANTH). (f) chl a:MYXO (diamonds, solid line) and chl a:scytonemins (squares, dashed line)

Canthaxanthin (CANTH), a diketo- $\beta$-carotene, accompanied the mono-keto ECHIN and resulted in chl a: CANTH ratios (Fig. 1 d) that greatly decreased $(\sim 30: 1$ to 2:1) with light intensity. Plotting chl $a$ to the sum of keto-carotenoids (Fig. 1e), it is observed that the trend is dominated by the influence of CANTH.

A highly polar pigment, suggested here to be a visible sunscreen $\left(\lambda_{\max }=440,562 \mathrm{~nm}\right)$ of presently unknown structure (UNKN), was present in Scytonema hoffmanii grown in high or intense photic flux even in the absence of UV wavelengths. That pigment is still under study but does have a scytonemin (SCYTO)type nucleus (C. Grant \& J. Louda unpublished data). The reduced (SCYTO-red) and oxidized (SCYTO-ox) forms of SCYTO, a dimeric indole-phenol (GarciaPichel et al. 1992, Proteau et al. 1993), were present and increased with increasing light levels.

Both the ratios of chl a:MYXO (Fig. 1f) and chl a: SCYTO (oxidized plus reduced: dashed trace in Fig. 1f) decreased with increasing light intensity, indicating photoprotective roles for each. Under intense light conditions the chl a:SCYTO ratios averaged only $0.4: 1$ to $0.1: 1$, indicating a 2.5 - to 10 -fold molar excess, relative to chl $a$, of SCYTO.

\section{Chlorophyta (green algae)}

Pigments found in the green algae were chlide $a_{\text {, }}$ neoxanthin (NEO), VIOLA, ANTH, LUT, ZEA, chl $b$, chl a-allo, chl $a$, chl $a^{\prime}$, pheophytin a (PTINa), and BETA. Chlide $a$ and PTINa were in extremely low amounts, likely representing minor senescence products (Louda et al. 1998, 2002) and confirming that the cultures were viable with little if any alteration of biomarker pigments (cf. Louda 2008)

Pigment arrays and light-related changes in the desmids Closterium acerosum and Cosmarium turpinii were identical. Chl $a$ to $\mathrm{chl} b$ values (Fig. 2a) were stable across tested light levels. The ratios were consistent at about 2.6:1 between 100 and $300 \mu \mathrm{mol}$ quanta $\mathrm{m}^{-2} \mathrm{~s}^{-1}$ with an increase ( 3.1:1), representing a rela- 
tive decrease in chl $b$, in low light. Chl a:LUT ratios (Fig. 2a) dropped with increasing intensity, indicating a photoprotective function for LUT (cf. Demmig-Adams \& Adams 2006); $\mathrm{R}^{2}$ values were 0.6 to $0.7: 1$ for $\mathrm{chl}$ a: LUT and 0.8 for chl $a: c h l b$ for both species. Data for chl a:LUT from both species often co-plotted such that the triangles (Closterium) and circles (Cosmarium) are indistinguishable in Fig. 2a.

The concentration of chl a cell-1 (Fig. 2b) decreased more than 4 -fold as light increased from 44 to 1700 umol quanta $\mathrm{m}^{-2} \mathrm{~s}^{-1}$. Thus, decreasing ratios of chl $a$ to other pigments in many instances are due to decreasing chl a concentration, while other pigments remain at nearly stable concentrations. For example, in these cases, chl a goes from about 400 to $200 \mathrm{fg} \mathrm{cell}^{-1}$ as chl a: LUT goes from about 10 to 4:1. Additionally, the slight decrease in chl $a$ :chl $b$ ratios in response to increasing light suggests that the cellular content of both chlorophylls are decreasing, but chl $b$ is decreasing faster than chl $a$ with increasing light.
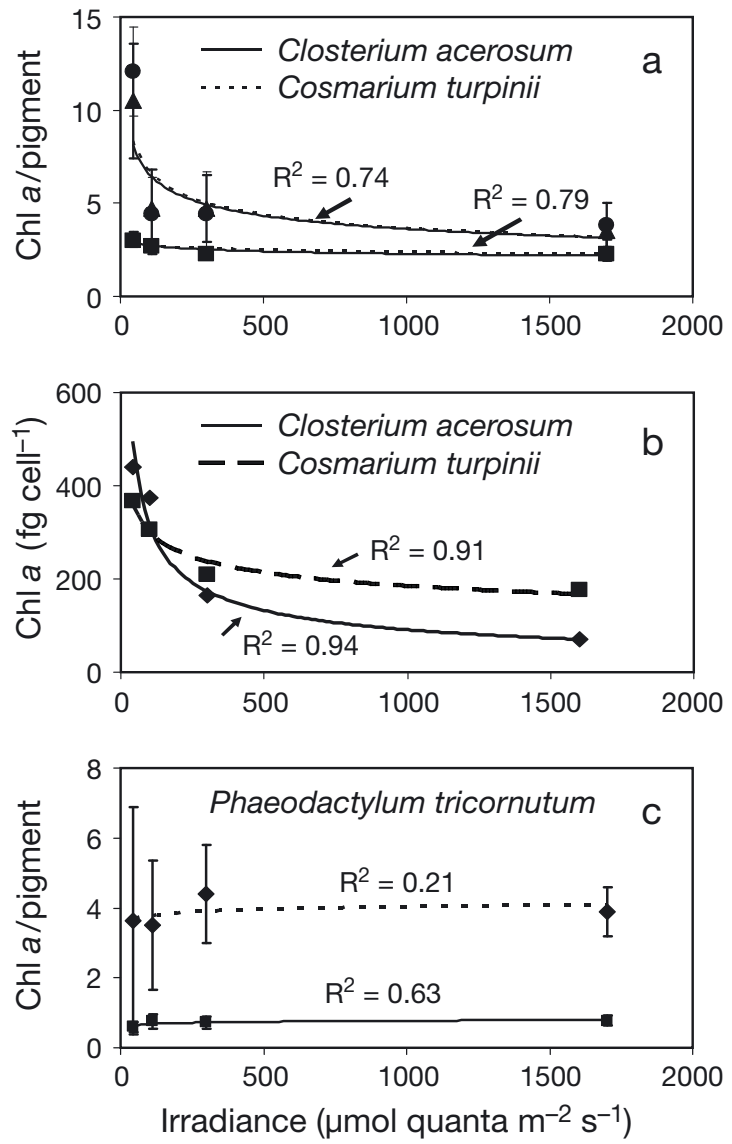

ZEA was not detected in the lowest light cultures. At other light levels the LUT:ZEA ratio (not plotted here) was about 12:1 (100-300 $\mu \mathrm{mol}$ quanta $\left.\mathrm{m}^{-2} \mathrm{~s}^{-1}\right)$ and dropped to about 8:1 under intense light. Chl a:ZEA was around 45 to $60: 1$ in the moderate and high light and about 30 to 35:1 in intense light. Other pigments (neoxanthin, violaxanthin, antheraxanthin) as part of the 'xanthophyll cycle' gave sporadic ratios to each other and to chl $a$. The VIOLA:NEO ratios in low light were about 0.5:1 and then leveled out at about unity at higher light levels.

\section{Chrysophyta, Bacillariophyceae (diatoms)}

The diatoms investigated were Phaeodactylum sp., tentatively $P$. tricornutum, and Navicula sp. Both species contained chlide $a_{1} \mathrm{chl} c_{1} / c_{2}$ (chl $c$ hereafter), pyrochlorophyllide a (pchlide a), FUCO, DD, DX, chl a-allo, chl $a$, chl $a^{\prime}$, and BETA.
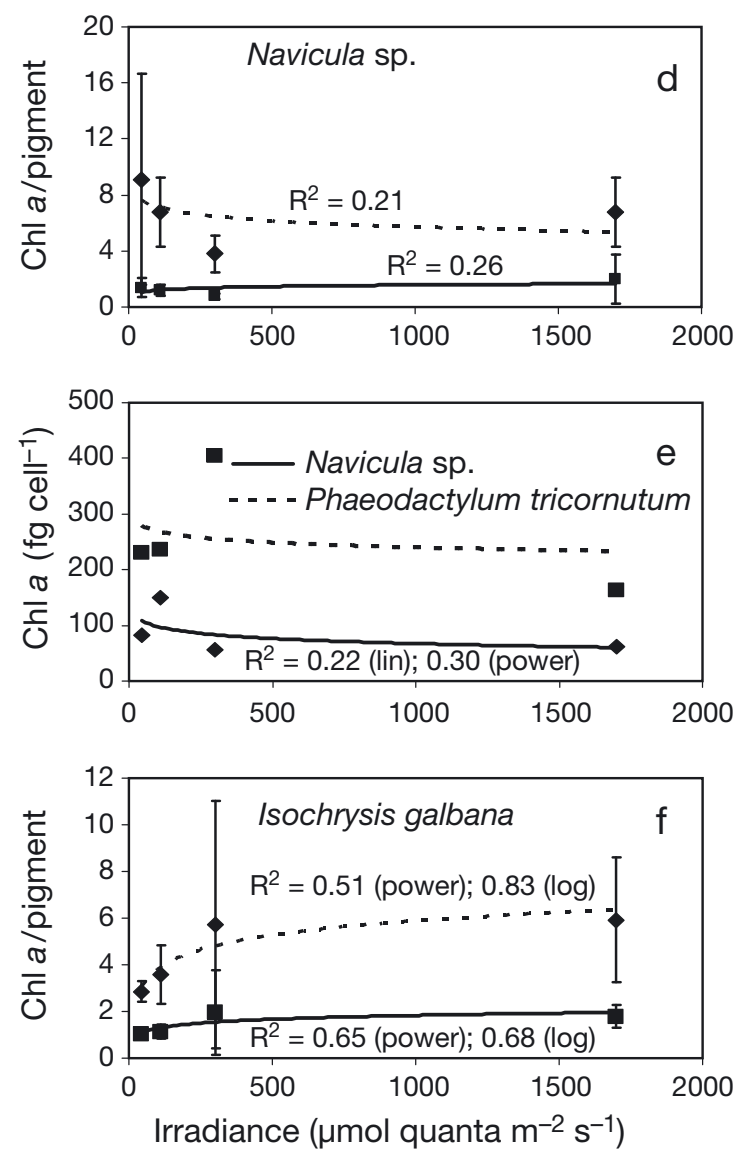

Fig. 2. (a,b) Chlorophyta; Closterium acerosum (solid traces) and Cosmarium turpinii (dotted traces). (a) Pigment ratios versus photic flux density (PFD) chl $a: \mathrm{chl} b$ (lower, diamonds and squares) and chl a:lutein (LUT; upper, triangles and solid circles), (b) chl a content cell ${ }^{-1}$ for $C$. acerosum ( diamonds, solid trace) and C. turpinii (squares, dashed trace). (c-e) Chromophyta, Bacillariophyceae: chl a:fucoxanthin (FUCO) (squares) and chl a:chl (i.e. chl $C_{1} / C_{2}$ ) $C$ (diamonds) versus light intensity for (c) Phaeodactylum tricornutum and (d) Navicula sp.; (e) chl a cell ${ }^{-1}$ versus light intensity for $P$. tricornutum (squares, dashed trace) and Navicula sp. (diamonds, solid trace); (f) Haptophyta, Isochrysis galbana; chl a:FUCO (squares, solid trace) and chl a:chl $c$ (diamonds, dashed trace) 
Only chl a:chl $c$ and chl a:FUCO gave trends versus light intensity that did not undergo 5-fold to an order of magnitude or greater changes (Fig. 2c,d). Chl a:chl $C$ was relatively stable at about $4: 1$ for Phaeodactylum sp. but dropped from about 9:1 to 5.5:1 in Navicula sp. Additionally, the chl a:chl $C$ values for both species had very large SDs in low light conditions (Fig. 2c,d). On the other hand, both diatoms gave chl $a$ :FUCO ratios about unity $(\sim 0.85: 1$, Fig. $2 \mathrm{c}_{i} \sim 1.1: 1$, Fig. 2 d) and did so with extremely low SDs, except for the intense light data from Navicula sp.

The contents of chl a cell ${ }^{-1}$ (Fig. 2e) decreased from about 250 to $150 \mathrm{fg} \mathrm{cell}^{-1}$ in Phaeodactylum and from about 100 to $60 \mathrm{fg} \mathrm{cell}^{-1}$ in Navicula.

\section{Chrysophyta, Prymnesiophyceae: Isochrysis galbana}

I. galbana contained chlide $a$, chl $c$, FUCO, DD, DIATO, chl $a$-allo, chl $a$, chl $a^{\prime}, \beta$-carotene (ALPHA), BETA, and pheophytin-a (PHTINa). Phytylated chl $c$ (cf. 'T-ISO' in Zapata \& Garrido 1997) was quite low in abundance. Given its close elution to chl a-allomer on our system, it could serve as an indication of this taxon but would be difficult to use as a routine biomarker. Zapata \& Garrido (1997) used a polymeric column and discussed the coelution with chl a-allo on monomeric systems, such as used herein. Soret absorption of the phytylated chl $c$ is at about $456 \mathrm{~nm}$ and is easily seen on the low energy side of the Soret band $(\sim 432 \mathrm{~nm})$ of $\mathrm{chl} a$ as a distinct inflection and could easily be confirmed with the second derivative.

As Isochrysis galbana is a non-19'-alkanoyloxyfucoxanthin-containing haptophyte, the most usable marker pigment for this species was FUCO, with the chl a:FUCO ratios (Fig. 2f) remaining between 1.1:1 and 2:1 from the low to the higher light experiments, respectively.

\section{Pyrrophyta (dinoflagellates)}

Amphidinium carteri contained chl $c$, PERI, dinoxanthin (DINO), DD, DX, chl $a$-allo, chl $a$, chl $a^{\prime}$, and BETA, as well as 2 glycosylated carotenoids (P-457and P-468). The chl a:PERI ratios (Fig. 3a) varied between 0.7:1 and 1.2:1. An increase in this ratio to nearly $2: 1$ was observed for growth under intense illumination. The chl a:chl $c$ ratio (Fig. 3a) was 1.9:1 in low to high light and 2.2:1 in intense light.

Ratios of chl $a$ to either chl $c$ or PERI for cultures grown under intense radiation exhibited very large variability, as indicated by large SDs in Fig. 3a.
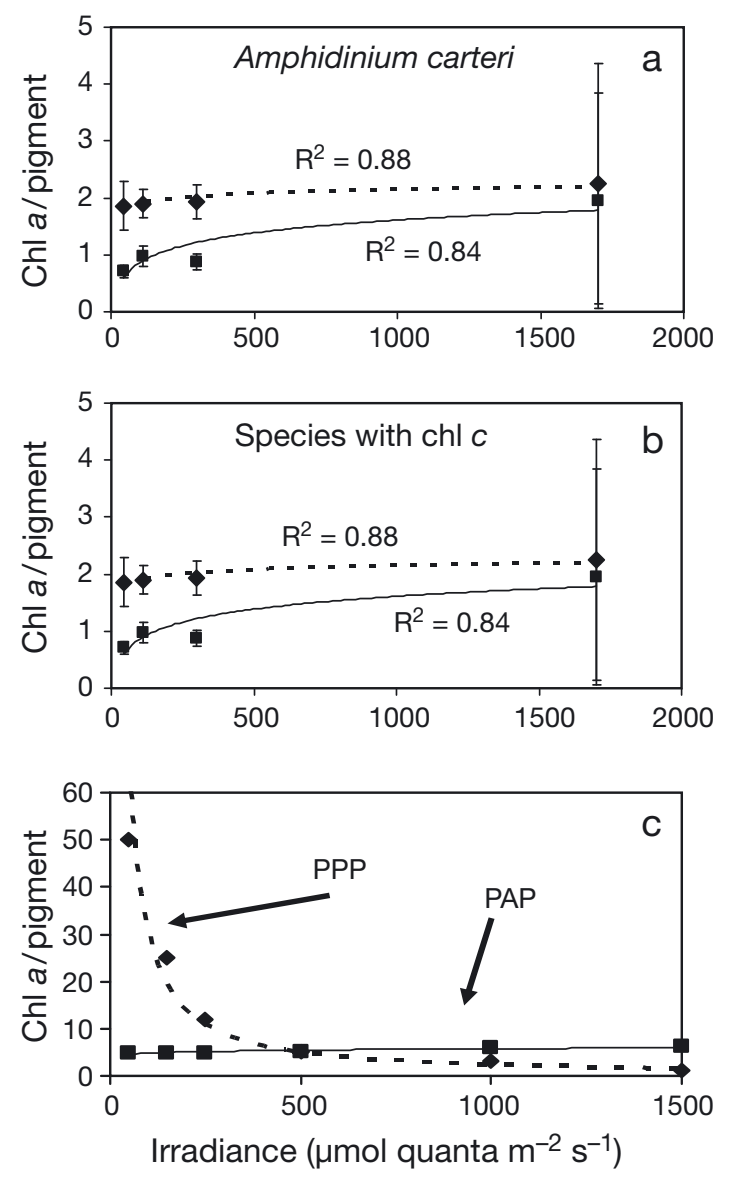

Fig. 3. (a) Dinophyta, Amphidinium carteri; chl a:peridinin (PERI; squares, solid trace) and $\mathrm{chl} a: \mathrm{chl} c$ (diamonds, dashed trace) versus light intensity. (b) chl a:diadinoxanthin versus light intensity for all chl c-containing species (Phaeodactylum tricornutum, Navicula sp., A. carteri, Gymnodinium sp., Isochrysis galbana) investigated herein. (c) Generalized (hypothetical) plot of photosynthetic accessory pigments (PAPs) and photoprotective pigments (PPPs) versus light intensity (see Results and Conclusion)

\section{Chromophyte xanthophyll cycle pigments}

The ratio of chl a:DD (Fig. 3b), or DD+DX (not shown), for these 5 species decreased from low to intense light, often by an order of magnitude (e.g. 20 to 2:1 in diatoms).

\section{DISCUSSION}

\section{Cyanobacteria}

Marker pigments for cyanobacteria are typically ZEA and/or ECHIN. Ratios of chl a:ZEA = 1.1:1 and chl $a: E C H I N=11.0: 1$ have been used for estimating coccoidal or filamentous cyanobacteria, respectively, in Florida Bay (Louda et al. 2000, Louda 2008) and Ever- 
glades (Hagerthey et al. 2006) studies. Similar ratios have been previously reported for samples grown without light or nutrient limitations (Wilhelm et al. 1991, Barlow et al. 1995).

The decrease in chl a:ZEA ratios for Anacystis nidulans (Fig. 1a) from about 2.6:1 to 1.5:1 and then to 1.0:1 with increasing light intensity suggests that ZEA functions to protect the species from photodamage (cf. Paerl et al. 1983, Bidigare et al. 1989). We previously found that Synechococcus sp. (possibly S. elongatus) had chl a:ZEA ratios of 2.5:1 or 1.0:1 in the dark brown humic waters of Whitewater Bay or the clearer waters of Florida Bay proper, respectively (Louda 2008). Even though ZEA acts as a PPP in A. nidulans, it is still is required as a marker pigment for coccoidal cyanobacteria lacking other carotenoids. ZEA does occur in the chlorophytes as well, but in very reduced concentrations. Aside from chl $a$, the other main pigment in A. nidulans is BETA, and since this pigment is nearly omnipresent in oxygenic phototrophs, it is not a suitable marker pigment. The decrease in the ratio of chl a:ZEA is explained wholly or partly by decreases in cellular chl a contents as previously reported for $A$. nidulans (Allen 1968) and with the largest decreases occurring above $300 \mu \mathrm{mol}$ photons $\mathrm{m}^{-2} \mathrm{~s}^{-1}$ (cf. Utkilen et al. 1983).

Nichols (1973) found that many freshwater filamentous cyanobacteria have a wide range of carotenoids (e.g. ECHIN, MYXOs, CANTH) not found in picoplanktonic cyanobacteria. In the present study, this observation holds for Lyngbya sp. and Scytonema sp. As such, we used ECHIN as the marker of choice for filamentous cyanobacteria. Thus, cyanobacteria chl a contributions include both back calculations from ratios to ECHIN (filamentous) and ZEA (coccoidal). Even though chl a:ECHIN ratios for these species are different, they are relatively stable with changing irradiance, and ECHIN is thus the most likely marker. Microscopic examination of the community would aid in picking the best ratio once the dominant species is identified. For Lyngbya sp., the chl a:ECHIN ratio is around 20:1, while that for Scytonema sp. is around 13:1. Previous work in our laboratory with Anabaena flos-aquae and Microcystis aeruginosa at different irradiance levels yielded chl a:ECHIN ratios of 11:1 (Skoog 2003, Skoog \& Louda 2003). The filamentous nonheterocystous genus Lyngbya is a worldwide bloom form and L. majuscule is of growing concern in tropical/sub-tropical waters (Paul et al. 2005).

The increase in CANTH with increased light intensity, giving dramatically decreasing chl a:CANTH (Fig. 1d) and correspondingly decreasing chl a:total keto-carotenoids (KETOs: Fig. 1e), points to a photoprotective function for CANTH. On the other hand, the relative stability of chl $a$ :ECHIN reveals that ECHIN is linked stoichiometrically to the photosynthetic reaction center as an accessory pigment. As total chl a decreases with increased light, the slight increase in chl a:ECHIN confirms that ECHIN acts as a PAP rather than strictly as a PPP. This slight increase in the ratio of chl $a$ to taxon-specific PAPs is also found in the diatoms and dinoflagellates investigated herein. Perhaps, in higher light conditions, antennae chl a may be photon saturated and require less energy input from the accessory pigments.

As the amount of ECHIN decreased only slightly during large increases in the relative amounts of CANTH, it appears that CANTH serves a much stronger photoprotective role than does ECHIN (cf. Lakatos et al. 2001).

Both the ratios of chl a:MYXO (Fig. 1f) and the SCYTOs (oxidized plus reduced) decreased dramatically with increasing light intensity, indicating photoprotective roles for each. One report stated that MYXO may not be a PAP but that it is required for thylakoid organization or cell wall function/stability (Mohamed et al. 2005). We think that these functions are not mutually exclusive.

\section{Chlorophyta (green algae)}

Closterium acerosum and Cosmarium turpinii are green algae that possess the same signature pigments. Chl $b$ was the best quantitative marker pigment for these 2 species, and the Chlorophyta in general, with chl a:chl $b$ ratios at around 2.5:1 for C. acerosum and around 2:1 for $C$. turpinii, over the range of light levels investigated. The chl $a$ :chl $b$ ratio in chl $b$-containing organisms ranges from 2:1 to 3:1 (Halldal 1970, Strain et al. 1971, Meeks 1974), and our data confirm this.

\section{Chrysophyta, Bacillariophyceae (diatoms)}

FUCO and chl $c$ are the main accessory lightharvesting pigments of diatoms (Stauber \& Jeffrey 1988). The diatoms used in this study, Phaeodactylum sp. and Navicula sp., exhibited the characteristic pigments of diatoms with FUCO as the marker pigment for chl a divisional estimation. The molar ratios found during this study were about 0.75:1 for Phaeodactylum sp. and 1.1:1 for Navicula sp. Chl a:FUCO (molar converted) ratios of 2.34:1 (Gieskes et al. 1988), 1.21:1 (Wilhelm et al. 1991), and 1.8 to 2.6:1 (Garibotti et al. 2003) have been reported from studies on North Sea, Pacific, and Antarctic waters.

Both species showed relatively stable ratios of chl a: chl $C$, even though they did not compare well with each other. The chl a:chl $c$ ratios for Navicula sp. were 
around 6:1 and about 4.1 for Phaeodactylum sp. Baumann et al. (1994) suggested a species-specific chl a: chl $c$ ratio. This would prove to be difficult if a mixed algal sample were being analyzed, and as such, chl a divisional estimates would not be calculated correctly. For example, chl $C_{2}$ also occurs in dinoflagellates, prymnesiophytes, cryptophytes, and others (see Jeffrey \& Vesk 1997, Jeffrey \& Wright 2006). For this reason, ' $\mathrm{chl} C$ ' is not considered herein as a marker pigment for determining the chl a contributions unless HPLC systems such as C8 (Zapata et al. 2000, 2004) designed for separation of the 'chl $C$ ' were employed in addition to or in place of a C18 system. Chl $C_{3}$, while separated from $-C_{1} / C_{2}$ on our system, was not encountered in any species tested during the present study.

\section{Pyrrophyta, Dinophyceae (dinoflagellates)}

PERI has long been used as the quantitative marker pigment for 'peridinin-containing' algae belonging to the division Dinophyceae (Johansen et al. 1974, Jeffrey et al. 1975). The chl a:PERI ratios varied between 0.8:1 and 1.0:1 for Amphidinium carteri grown under low to high light. These ratios are lower than the 1.5:1 conversion factor used by Louda (2008) to estimate the chl a contributed from dinoflagellates in studies of Florida Bay. However, the ratio of chl a:PERI ( 2.0:1) in intense light (Fig. 3a) easily encompasses the calculations from Florida Bay, an intense light environment. Chl a:PERI ratios as high as 2.35:1 (Everitt et al. 1990, Ondrusek et al. 1991) and 3.96:1 (Barlow et al. 1995) have been reported.

The chl a:chl $c$ ratios for both species studied shows some stability around 2:1 but, as discussed above, since the chl $c$ are common light-harvesting pigments across different algal groups, they cannot be standalone division/class estimators in single pigment determinations. They may, however, be helpful in mathematically advanced algorithms such as CHEMTAX (Mackey et al. 1996, Wright \& Jeffrey 2005) or BCE (Van den Meersche et al. 2009), especially when HPLC systems (e.g. C8) that completely separate all chl $C$ forms are included.

\section{Chrysophyta, Prymnesiophyceae}

The main photosynthetic light-harvesting pigments for this division are $\operatorname{chl} a_{1}, \operatorname{chl} c$, and FUCO (Montero et al. 2002) plus a wide assortment of ' $\operatorname{chl} C^{\prime}$ and FUCO derivatives (Zapata et al. 2004).

For the strain (T-ISO) of Isochrysis galbana examined here, we found chl a:FUCO values to change slowly as light intensity increased. The chl a:FUCO ratios varied between $1: 1$ and $1.6: 1$ to just under $2: 1$. Chl a:FUCO ratios of 1.46:1 (Vidussi et al. 2000), 1.18:1 (Descy et al. 2000), 1.69:1 (Barlow et al. 1993), and 3.1 to 3.7 (Zapata et al. 2004) have been reported for studies done on different factors that affect changes in pigment relationships in phytoplankton. Note that we used molar ratios, and the ratios originally reported on a w/w basis were converted to molar ratios for this report. Chl a:chl $C$ ratios of I. glabana increased from about 3:1 to 6:1 with increasing light intensity. The $I$. galbana cultured in our study would fall in the 'Type-3 Haptophyte' array as defined by Zapata et al. (2004). Their 2 strains, grown at 60 to $70 \mu \mathrm{mol}$ quanta $\mathrm{m}^{-2} \mathrm{~s}^{-1}$ (12L:12D) gave chl a:FUCO of 3.70:1 and 3.11, as converted to molar ratios.

A different sample of 'T-ISO', provided by the Harbor Branch Oceanographic Institution (Ft. Pierce, FL, USA), contained phytylated chl $c$ (Louda unpubl. 2009). However, that sample was not cultured during the present study. Phytylated chl $c$ (cf. Zapata et al. 2004) would be useful in better defining mixed natural cultures containing Isochrysis galbana.

Without the wide variety of $\mathrm{chl} c$ and FUCO derivatives given for numerous haptophytes (Zapata et al. 2004), the pigment array of the Isochrysis galbana strain studied here would place this isolate with diatoms and other chrysophytes.

\section{CONCLUSIONS}

Throughout this study, we found that the ratio of chl $a$ to various other lipophilic pigments either decreased rapidly with increasing light intensity or remained relatively stable with sporadic slight increases. It is therefore concluded that those pigments which maintain some level of stability in their relationship (stoichiometry) to chl a are primary PAPs. On the other hand, pigments which exhibit relative significant increases in relation to $\mathrm{chl} a$, thus giving decreasing chl a:pigment ratios with increasing photic flux, are concluded as being mainly PPPs. That is not to say that a pigment acting 'mainly' as a PPP cannot also be involved in energy transfer during photosynthesis (cf. Demmig-Adams \& Adams 2006 and references therein). As noted, chl a content per cell decreases with increasing photic flux, and this phenomenon partially or wholly explains the decreasing chl a:PPP ratios observed.

Fig. 3c shows the generalized trends for PAP- and PPP-type pigments. The ratio values of chl $a$ to either PPP or PAP are hypothetical but reflect the ranges reported herein. Thus, PAP-type pigments include ECHIN (cyanobacteria), chl $b$ (chlorophytes), FUCO (diatoms, other chrysophytes), and PERI (PERI-containing dinoflagellates). PPP-type pigments include 
ZEA, CANTHA, MYXO, and SCYTO in cyanobacteria; LUT and all 'xanthophyll-cycle' pigments (ZEA, VIOLA, ANTH, NEO) in chlorophytes; and DD + DX in chrysophytes and dinoflagellates.

When using any of the PPP-type pigments for community estimation, consideration of the average light field (photo flux density, PFD) is an absolute requirement. Given slight differences in the ratio of chl a:PAP pigments, light field measurement should also be factored into all determinations. When using chl $a$ as a proxy e.g. for biomass and organic carbon, the average light field data are also a much needed metric, as the amount of chl a per cell decreases with increasing light level.

In many cases, the majority of the decreases in chl $a$ : marker (viz. PPP) pigment ratios is due to decreasing amounts of chl $a$ with increasing PFD. Chl a:PAP ratios change very little with light.

The measure of PAR during sampling and monitoring can provide ancillary data with which to improve pigment-based chemotaxonomic estimates of microalgal community structure and dynamics.

Acknowledgements. This work has been supported in part by past contracts to J.W.L. from the Division of Marine Fisheries, National Oceanographic and Atmospheric Administration (NOAA), and the South Florida Water Management District (SFWMD). The assistance of J. Morrison of the Living Materials section of Carolina Biological Supply during the early stages of culture material selection is noted. We thank P. Mongkhonsri for expert assistance in routine laboratory functions and maintenance, especially HPLC operations. This study was performed during the pursuit of the MS and PhD degrees by C.S.G.

\section{LITERATURE CITED}

Allen MM (1968) Photosynthetic membrane system in Anacystis nidulans. J Bacteriol 96:836-841

Barlow RG, Mantoura RFC, Gough MA, Fileman TW (1993) Pigment signatures of the phytoplankton composition in the northeastern Atlantic during the 1990 spring bloom. Deep-Sea Res II 40:459-477

Barlow RG, Mantoura RFC, Peinert RD, Miller AEJ, Fileman TW (1995) Distribution, sedimentation and fate of pigment biomarkers following thermal stratification in the western Alboran Sea. Mar Ecol Prog Ser 125:279-291

Basch LV (1996) Effects of algal and larval densities on development and survival of asteroid larvae. Mar Biol 126: 693-701

Baumann MEM, Lancelot C, Brandini FP, Sakshaug E, John MD (1994) The taxonomic identity of cosmopolitan prymnesiophyte Phaeocyctis: a morphological and ecophysiological approach. J Mar Syst 5:5-22

Bidigare RR, Schofield O, Prezelin BB (1989) Influence of zeaxanthin on quantum yield of photosynthesis of Synechococcus clone WH7803 (DC2). Mar Ecol Prog Ser 56: $177-188$

Britton G (1995) UV/visible spectroscopy. In: Britton G, Liaaen-Jensen S, Pfander H (eds) Carotenoids. Vol IB:
Spectroscopy. Birkhauser-Verlag, Basel, p 13-62

Carreto JI, Montoya N, Akselman R, Carignan MO, Silva RI, Cucchi-Colleoni DA (2008) Algal pigment patterns and phytoplankton assemblages in different water masses of the Río de la Plata maritime front. Cont Shelf Res 28: $1589-1606$

Demmig-Adams B (1990) Carotenoids and photoprotection in plants: a role for the xanthophyll zeaxanthin. Biochim Biophys Acta 1020:1-24

Demmig-Adams B, Adams WE (2006) Tansley review: photoprotection in an ecological context: the remarkable complexity of thermal energy dissipation. New Phytol 172: $11-21$

> Descy JP, Metens A (1996) Biomass-pigment relationships in potamoplankton. J Plankton Res 18:1557-1566

$>$ Descy JP, Higgins HW, Mackey DJ, Hurley JP, Frost TM (2000) Pigment ratios and phytoplankton assessment in northern Wisconsin lakes. J Phycol 36:274-286

Eker-Develi E, Berthon JF, van der Linde D (2008) Phytoplankton class determination by microscopic and HPLCCHEMTAX analyses in the southern Baltic Sea. Mar Ecol Prog Ser 359:69-87

- Everitt DA, Wright SW, Volkman JK, Thomas DP, Lindstrom EJ (1990) Phytoplankton community compositions in the western equatorial Pacific determined from chlorophyll and carotenoid pigment distributions. Deep-Sea Res 37: 975-997

Fleming ED, Castenholz RW (2007) Effects of periodic desiccation on the synthesis of the UV-screening compound, scytonemin, in cyanobacteria. Environ Microbiol 9: 1448-1455

Francis GW, Hertzberg S, Andersen K, Liaaen-Jensen S (1970) New carotenoid glycosides from Oscillatoria limosa. Phytochemistry 9:629-635

Garcia-Pichel F, Sherry ND, Castenholz RW (1992) Evidence for an ultraviolet sunscreen role of the extracellular pigment scytonemin in the terrestrial cyanobacterium Chlorogloeopsis sp. Photochem Photobiol 56:17-23

> Garibotti IA, Vernet M, Kozlowski WA, Ferrario M (2003) Composition and biomass of phytoplankton assemblages in coastal Antarctic waters: a comparison of chemotaxonomic and microscopic analyses. Mar Ecol Prog Ser 247: $27-42$

Gieskes WWC, Kraay GW (1983) Unknown chlorophyll a derivatives in the North Sea and the tropic Atlantic Ocean revealed by HPLC analysis. Limnol Oceanogr 28:757-766

Gieskes WWC, Kraay GW, Nontji A, Setiapermana D, Sutomo (1988) Monsoonal alteration of a mixed and a layered structure in the phytoplankton of the euphotic zone of the Banda Sea (Indonesia): a mathematical analysis of algal fingerprints. Neth J Sea Res 22:123-137

> Goericke R, Montoya JP (1998) Estimating the contribution of microalgal taxa chlorophyll $a$ in the field-variations of pigment ratios under nutrient- and light-limited growth. Mar Ecol Prog Ser 169:97-112

Green BR, Durnford DG (1996) The chlorophyll-carotenoid proteins of oxygenic photosynthesis. Annu Rev Plant Physiol Plant Mol Biol 47:685-714

Greisberger S, Teubner K (2007) Does pigment composition reflect phytoplankton community structure in differing temperature and light conditions in a deep alpine lake? An approach using HPLC and delayed fluorescence (DF) techniques. J Phycol 43:1108-1119

Guillard RL (1975) Culture of phytoplankton for feeding marine invertebrates. In: Smith WL, Chanley MH (eds) Culture of marine invertebrate animals. Plenum Press, New York, p 29-60 
Hager A (1980) The reversible, light induced conversions of xanthophylls in the chloroplast. In: Czygan FC (ed) Pigments in plants. Fischer, Stuttgart, p 57-79

Hagerthey SE, Louda JW, Mongkhonsri P (2006) Evaluation of pigment extraction methods and a recommended protocol for periphyton chlorophyll a determination and chemotaxonomic assessment. J Phycol 42:1125-1136

Halldal P (1970) Photosynthetic apparatus of microalgae. In: Halldal P (ed) Microbiology of microorganisms. Wiley Interscience, New York, p 17-55

Jeffrey SW (1997) Application of pigment methods to oceanography. In: Jeffrey SW, Mantoura RFC, Wright SW (eds) Phytoplankton pigments in oceanography. SCORUNESCO, Paris, p 124-166

Jeffrey SW, Vesk M (1997) Introduction to marine phytoplankton and their pigment signatures. In: Jeffrey SW, Mantoura RFC, Wright SW (eds) Phytoplankton pigments in oceanography. SCOR-UNESCO, Paris, p 34-87

Jeffrey SW, Wright SW (2006) Photosynthetic pigments in marine microalgae: insights from cultures and the sea. In: Subba Rao DV (ed) Algal cultures, analogues of blooms and applications. Science Publishers, Enfield, NH, p 33-90

Jeffrey SW, Sielicki M, Haxo FT (1975) Chloroplast pigment patterns in dinoflagellates. J Phycol 11:374-384

Jeffrey SW, Llewellyn CA, Barlow RG, Mantoura RFC (1997) Pigment processes in the sea: a selected bibliography. In: Jeffrey SW, Mantoura RFC, Wright SW (eds) Phytoplankton pigments in oceanography. SCOR-UNESCO, Paris, p 167-178

Jeffrey SW, Wright SW, Zapata M (1999) Recent advances in HPLC pigment analysis of phytoplankton. Mar Freshw Res 50:879-896

Johansen JE, Svec WA, Liaaen-Jensen S, Haxo FT (1974) Carotenoids of Dinophyceae. Phytochemistry 13:2261-2271

Lakatos M, Bilger W, Budel B (2001) Carotenoid composition of terrestrial Cyanobacteria: response to natural sunlight conditions in open rock habitats in Venezuela. Eur J Phycol 36:367-375

Laza-Martinez A, Seoane S, Zapata M, Orive E (2007) Phytoplankton pigment patterns in a temperate estuary: from unialgal cultures to natural assemblages. J Plankton Res 29:913-929

Leavitt PR, Carpenter SR (1990) Aphotic pigment degradation in the hypolimnion: implications for sedimentation studies and paleolimnology. Limnol Oceanogr 35:520-534

Leonardos N, Harris GN (2006) Comparative effects of light on pigments of two strains of Emiliania huxleyi (Haptophyta). J Phycol 42:1217-1224

Lewitus AJ, White DL, Tymowski RG, Geesey ME, Hymel SN, Noble PA (2005) Adapting the CHEMTAX method for assessing phytoplankton taxonomic composition in southeastern U.S. Estuaries 28:160-172

Louda JW (1993) The biogeochemistry of tetrapyrrole pigments, emphasizing chlorophyll. PhD dissertation, University of South Florida, Tampa, FL

> Louda JW (2008) Pigment-based chemotaxonomy of Florida Bay phytoplankton; development and difficulties. J Liq Chromatogr Relat Technol 31:295-323

> Louda JW, Li J, Liu L, Winfree MN, Baker EW (1998) Chlorophyll degradation during senescence and death. Org Geochem 29:1233-1251

Louda JW, Loitz JW, Rudnick DT, Baker EW (2000) Early diagenetic alteration of chlorophyll $a$ and bacteriochlorophyll $a$ in a contemporaneous marl ecosystem. Org Geochem 31:1561-1580

Louda JW, Liu L, Baker EW (2002) Senescence- and death- related alteration of chlorophylls and carotenoids in marine phytoplankton. Org Geochem 33:1635-1653

- Mackey MD, Mackey DJ, Higgins HW, Wright SW (1996) CHEMTAX - a program for estimating class abundance from chemical markers: applications to HPLC measurements of phytoplankton. Mar Ecol Prog Ser 144:265-283

Mackey DJ, Higgins HW, Mackey MD, Holdsworth D (1998) Algal class abundances in the western equatorial Pacific: Estimation from HPLC measurements of chloroplast pigments using CHEMTAX. Deep-Sea Res I 45:1441-1468

> Mantoura RFC, Llewellyn CA (1983) The rapid determination of algal chlorophyll and carotenoid pigments and their breakdown products in natural waters by reversed phase high performance liquid chromatography. Anal Chim Acta 151:297-314

Meeks JC (1974) Chlorophylls. In: Stewart WDP (ed) Algal physiology and biochemistry. Blackwell Scientific, Oxford, p 161-175

Millie DF, Pearl HW, Hurley JP (1993) Microalgal pigment assessments using high performance liquid chromatography: a synopsis of organismal and ecological applications. Can J Fish Aquat Sci 50:2513-2527

> Mohamed HE, van de Meene AML, Robertson RW, Vermaas WFJ (2005) Myxoxanthophyll is required for normal cell wall structure and thylakoid organization in the cyanobacterium Synecocystis sp. strain PCC 6803. J Bacteriol 187: 6883-6892

> Montero O, Klisch M, Häder DP, Lubian LM (2002) Comparative sensitivity of seven marine microalgae to cumulative exposure to ultraviolet-b radiation with daily increasing doses. Bot Mar 45:305-315

Nichols BW (1973) Lipid composition and metabolism. In: Carr NG, Whitton BA (eds) The biology of blue green algae. Blackwell, Oxford, p 144-161

Ondrusek ME, Bidigare RR, Sweet ST, Defreitas DA, Brooks JM (1991) Distribution of phytoplankton pigments in the North Pacific Ocean in relation to physical and optical variability. Deep-Sea Res 38:243-266

> Paerl HW, Tucker J, Bland PT (1983) Carotenoid enhancement and its role in maintaining blue-green algal (Microcystis aeruginosa) surface blooms. Limnol Oceanogr 28: 847-857

> Paerl HW, Valdes LM, Pinckney JL, Piehler MF, Dybe J, Moisander PH (2003) Phytoplankton photopigments as indicators of estuarine and coastal eutrophication. Bioscience 53:953-964

Patoine A, Leavitt PR (2006) Century-long synchrony of fossil algae in a chain of Canadian prairie lakes. Ecology 87: $1710-1721$

Paul VJ, Thacker R, Banks K, Golubic S (2005) Benthic cyanobacterial bloom impacts on the reefs of South Florida (Broward County, USA). Coral Reefs 24:693-697

> Peeken I (1997) Photosynthetic pigment fingerprints as indicators of phytoplankton biomass and development in different water masses of the Southern Ocean during austral spring. Deep-Sea Res II 44:261-282

> Phlips EJ, Badylak S, Lynch TC (1999) Blooms of the picoplanktonic cyanobacterium Synechococcus in Florida Bay, a subtropical inner shelf lagoon. Limnol Oceanogr 44: 1166-1175

Pinckney JL, Richardson TL, Millie DF, Paerl HW (2001) Application of photopigment biomarkers for quantifying microalgal community composition and in situ growth rates. Org Geochem 32:585-595

Proteau PJ, Gerwick WH, Garcia-Pichel F, Castenholz R (1993) The structure of scytonemin, an ultraviolet sunscreen pigment from the sheaths of cyanobacteria. 
Experientia 49:825-829

Rodriguez F, Chauton M, Johnsen G, Andresen K, Olsen LM, Zapata M (2006) Photoacclimation in phytoplankton: implications for biomass estimates, pigment functionality and chemotaxonomy. Mar Biol 148:963-971

Schlüter L, Møhlenberg F, Havskum H, Larsen S (2000) The use of phytoplankton pigments for identifying and quantifying phytoplankton groups in coastal areas: testing the influence of light and nutrients on pigment/chlorophyll $a$ ratios. Mar Ecol Prog Ser 192:49-63

Skoog KO (2003) Pigment-based chemotaxonomy of phytoplankton communities in Lake Okeechobee, Florida. MS Thesis, Florida Atlantic University, Boca Raton, FL

Skoog KO, Louda JW (2003) Chemotaxonomic assessment of Lake Okeechobee phytoplankton: natural samples and in vitro experimentation into the effects of light levels. 67th Annu Meet Fla Acad Sci, Orlando, FL, March 21-22, 2003. Abstract SS-6

Stauber JL, Jeffrey SW (1988) Photosynthetic pigments in fifty-one species of marine diatoms. J Phycol 24:158-172

Strain HH, Cope BT, Svec WA (1971) Procedures for isolation, identification, estimation, and investigation of the chlorophylls. Methods Enzymol 23:452-476

Thayer SS, Bjorkman O (1992) Carotenoid distribution and de-epoxidation in thylakoid pigment-protein complexes from cotton leaves and bundle sheath cells of maize. Photosyn Res 33:213-226

Utkilen HC, Briseid T, Eriksson B (1983) Variation in photosynthetic membrane and pigment content with light intensity for Anacystis nidulans grown in continuous cultures. J Gen Microbiol 129:1717-1720

Van den Meersche K, Soetaert K, Van Oevelen D (2008)

Editorial responsibility: Warwick Vincent, Sante-Foy, Canada xsample(): an R function for sampling linear inverse problems. J Stat Softw 30 (Code Snippet 1):1-15

Vidussi F, Marty JC, Chiaverini J (2000) Phytoplankton pigment variations during the transition from spring bloom to oligotrophy in the northwestern Mediterranean Sea. Deep-Sea Res I 47:423-445

Wilhelm C, Rudolph I, Renner W (1991) A quantitative method based on HPLC-aided pigment analysis to monitor structure and dynamics of the phytoplankton assemblage - a study from Lake Meerfelder Maar (Eifel, Germany). Arch Hydrobiol 123:21-35

Wright SW, Jeffrey SW (1997) High-resolution HPLC system for chlorophylls and carotenoids of marine phytoplankton. In: Jeffrey SW, Mantoura RFC, Wright SW (eds) Phytoplankton pigments in oceanography. SCOR-UNESCO, Paris, p 327-342

Wright SW, Jeffrey SW (2005) Pigment markers for phytoplankton production. In: Volkman JK (ed) Handbook of environmental chemistry, Vol. 2N: marine organic matter, biomarkers, isotopes and DNA. Springer-Verlag, Berlin, p 71-104

Zapata M, Garrido JL (1997) Occurrence of phytylated chlorophyll $C$ in Isochrysis galbana and Isochrysis sp. (Clone T-ISO) (Prymnesiophyceae). J Phycol 33:209-214

Zapata M, Rodriquez F, Garrido JL (2000) Separation of chlorophylls and carotenoids from marine phytoplankton: a new HPLC method using a reversed phase C8 column and pyridine mobile phases. Mar Ecol Prog Ser 195:29-45

Zapata M, Jeffrey SW, Wright SW, Rodriquez F, Garrido JL, Clemenston L (2004) Photosynthetic pigments in 37 species (65 strains) of Haptophyta: implications for oceanography and chemotaxonomy. Mar Ecol Prog Ser 270:83-102

Submitted: June 4, 2010; Accepted: October 1, 2010

Proofs received from author(s): November 29, 2010 